\title{
Chronic $\Delta^{9}$-tetrahydrocannabinol administration reduces $\lg \mathrm{E}+\mathrm{B}$ cells but unlikely enhances pathogenic SIV $_{\text {mac251 }}$ infection in male Rhesus macaques of Chinese origin
}

\author{
Qiang Wei ${ }^{\# 1}$, Li Liü2,4, Zhe Cong ${ }^{\# 1}$, Xiaoxian Wu ${ }^{1}$, Hui Wang ${ }^{4}$, Chuan Qin ${ }^{1}$, Patricia \\ Molina $^{3,{ }^{*} \text {, and Zhiwei Chen }}{ }^{2,4,{ }^{*}}$ \\ ${ }^{1}$ Institute of Laboratory Animal Science, Chinese Academy of Medical Sciences and Peking Union \\ Medical College, No.5, Panjiayuan, Nanli, Chaoyang District, Beijing, People's Republic of China \\ ${ }^{2}$ AIDS Institute and Research Center for Infection and Immunology, Department of Microbiology, \\ Li Ka Shing Faculty of Medicine, The University of Hong Kong, 21 Sassoon Road, Hong Kong \\ SAR, People's Republic of China \\ ${ }^{3}$ Department of Physiology, The Louisiana State University Health Sciences Center at New \\ Orleans, 1901 Perdido Street, New Orleans, LA 70112, United States of America \\ ${ }^{4} \mathrm{HKU}$-AIDS Institute Shenzhen Research Laboratory and AIDS Clinical Research Laboratory, \\ Guangdong Key Lab of Emerging Infectious Diseases and Shenzhen Key Lab of Infection and \\ Immunity, Shenzhen Third People's Hospital, Guangdong Medical College, Shenzhen, 518112, \\ People's Republic of China \\ \# These authors contributed equally to this work.
}

\begin{abstract}
Delta9-tetrahydrocannabinol $\left(\Delta^{9}\right.$-THC) is the major psychoactive component of the cannabis plant. $\Delta^{9}$-THC has been used in the active ingredient of Marinol as an appetite stimulant for AIDS patients. Its impact on progression of HIV-1 infection, however, remains debatable. Previous studies indicated that $\Delta^{9}$-THC administration enhanced HIV-1 infection in huPBL-SCID mice but seemingly decreased early mortality in simian immunodeficiency virus (SIV) infected male Indian-derived rhesus macaques. Here, we determine the chronic effect of $\Delta^{9}$-THC administration $\left(0.32 \mathrm{mg} / \mathrm{kg}\right.$ or placebo-PBO, i.m., twice daily for 428 days) on $\mathrm{SIV}_{\mathrm{mac} 251}$ infected male Chinesederived rhesus macaques. Sixteen animals were divided into four study groups: $\Delta^{9}-\mathrm{THC}^{+} \mathrm{SIV}^{+}, \Delta^{9}-$ $\mathrm{THC}^{+} \mathrm{SIV}^{-}$, placebo (PBO)/SIV ${ }^{+}$and $\mathrm{PBO} / \mathrm{SIV}^{-}$(n=4/group). One-month after daily $\Delta^{9}-\mathrm{THC}$ or $\mathrm{PBO}$ administrations, macaques in groups one and three were challenged intravenously with

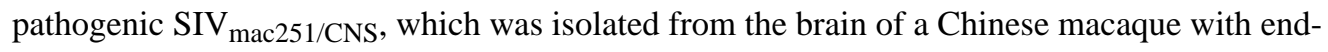
staged neuroAIDS. No significant differences in peak and steady state plasma viral loads were seen between $\Delta^{9}$-THC and PBO infected macaques. Regardless of $\Delta^{9}$-THC, all infected macaques
\end{abstract}

\footnotetext{
"Corresponding authors: Zhiwei Chen, AIDS Institute, Department of Microbiology, Li Ka Shing Faculty of Medicine, The University of Hong Kong, 21 Sassoon Road, Pokfulam, Hong Kong S.A.R., P.R. China, Phone: (852) 3917-9831; Fax: (852) 3917-9095, zchenai@hku.hk; Patricia Molina, Department of Physiology, The Louisiana State University Health Sciences Center at New Orleans, 1901 Perdido Street, New Orleans, LA 70112, USA, PMolin@1suhsc.edu.

Conflicts of Interest

The authors of this manuscript do not report conflict of interest.
} 
displayed significant drop of CD4/CD8 $\mathrm{T}$ cell ratio, loss of $\mathrm{CD} 4^{+} \mathrm{T}$ cells and higher persistent levels of $\mathrm{Ki} 67^{+} \mathrm{CD} 8^{+} \mathrm{T}$ cells when compared to uninfected animals. Moreover, long-term $\Delta^{9}$-THC treatment reduced significantly the frequency of circulating $\operatorname{IgE}^{+} \mathrm{B}$ cells. Only one infected macaque in the $\Delta^{9}-\mathrm{THC}^{+} \mathrm{SIV}^{+}$group died of simian AIDS with paralyzed limbs as compared with two deaths in the $\mathrm{PBO} / \mathrm{SIV}^{+}$group during the study period. These findings indicate that chronic $\Delta^{9}$-THC administration resulted in reduction of $\operatorname{IgE}^{+} \mathrm{B}$ cells, yet it unlikely enhanced pathogenic $\mathrm{SIV}_{\mathrm{mac} 251 / \mathrm{CNS}}$ infection in male Rhesus macaques of Chinese origin.

\section{Keywords}

cannabinoids; THC; SIV; IgE ${ }^{+}$B cell; Rhesus macaque; HIV-1; AIDS

\section{Introduction}

Delta9-tetrahydrocannabinol $\left(\Delta^{9}\right.$-THC) is the major psychoactive cannabinoid in the cannabis sativa (Croxford 2003). The biological function of $\Delta^{9}$-THC is mediated by interaction with two major G-protein-coupled cannabinoid receptors, namely CB1 and CB2 receptors (Felder and Glass 1998; Kaplan 2013; Pertwee 1997). While the CB1 receptor is preferentially expressed in the brain as the mediator of cannabis-induced neurobehavioral effects, the CB2 receptor is found primarily in peripheral immune system such as on the surface of T and B cells (Ameri 1999; Gorantla et al. 2010; Kaplan 2013). Theologically, the chronic administration of $\Delta^{9}$-THC may affect both central nerve system and immune system and, therefore, potentially modulate disease progression especially among patients infected with neurotropic HIV-1. This is a critical issue because the man-made Marinol, whose active ingredient is $\Delta^{9}$-THC, has been approved by the Food and Drug Administration as an appetite stimulant for the treatment of HIV-1-associated anorexia and weight loss (Abrams 1998; Riggs et al. 2012). HIV-1-positive marijuana smokers produced substantial and comparable increases in food intake (Haney 2002; Haney et al. 2007). It, however, the impact of $\Delta^{9}$-THC on HIV-1 infection remains under investigation.

In vitro studies indicated that $\Delta^{9}$-THC decreased constitutive production of IL-8, MIP-1alpha, MIP-1beta, and RANTES, changes that might worsen HIV-1 infection (Srivastava et al. 1998). Moreover, $\Delta^{9}$-THC administration suppressed immune function and enhanced HIV-1 infection in huPBL-SCID mice with significantly higher number of infected cells and viral loads (Roth et al. 2005). Similar enhancement effects, however, were not found in a randomized, prospective, controlled trial comparing the use of marijuana cigarettes (3.95\% THC), dronabinol (2.5 mg), and oral placebo in HIV-1-infected adults taking protease inhibitor-containing highly active antiretroviral therapy (HAART)(Bredt et al. 2002). One study indicated that $\Delta^{9}$-THC might reduce HIV-1 receptor expression on monocytes that diminished entry efficiency (Williams et al. 2014). In non-human primate models, chronic treatment with $\Delta^{9}$-THC seemingly decreased plasma and CSF viral loads and tissue inflammation, reducing morbidity and mortality of SIV-infected male Indian macaques (Molina et al. 2011b). Although there were no significant alterations in immune phenotype in animals, subsequent analysis indicated that $\Delta^{9}$-THC modulated duodenal T cell populations, favored a pro-Th2 cytokine balance, and decreased intestinal apoptosis (Molina 
et al. 2014). In contrast, chronic $\Delta^{9}$-THC administration, did not seem to protect SIVinfected female Indian rhesus macaques from early mortality (Amedee et al. 2014). These findings call for continued efforts to understand the impact of chronic $\Delta^{9}$-THC in a separate SIV/macaque model.

Based on these publications, we hypothesized that chronic $\Delta^{9}$-THC might affect morbidity and mortality in male SIV-infected Chinese-derived macaques. To test this hypothesis, we sought to determine the effects of long-term $\Delta^{9}$-THC treatment using four groups of a total of 16 male Chinese macaques with or without $\operatorname{SIV}_{\text {mac251 infection. }}$

\section{Materials and Methods}

\section{Animals}

Sixteen male Chinese rhesus macaques were housed in the facility at the Institute of Laboratory Animal Science (ILAS), Chinese Academy of Medical Sciences and Peking Union Medical College. They were negative in tests of SIV, herpes B virus, and simian Tlymphotropic virus. The Institutional Animal Care and Use Committee (IACUC) of Louisiana State University Health Sciences Center and ILAS approved our animal experimental protocols for ethics and care. Post infection, biospecimen collection was performed with animals under anesthesia using ketamine hydrochloride $(10 \mathrm{mg} / \mathrm{kg})$ in ILAS' Animal Bio-Safety Level 3 (ABSL-3) laboratory, which is accredited by the Association for Assessment and Accreditation of Laboratory Animal Care (AAALAC).

\section{$\Delta^{9}$-THC administration}

Chinese macaques were divided into four study groups: $\Delta^{9}-\mathrm{THC}^{+} \mathrm{SIV}^{+}, \Delta^{9}-\mathrm{THC}^{+} \mathrm{SIV}^{-}$, $\mathrm{PBO} / \mathrm{SIV}^{+}$and $\mathrm{PBO} / \mathrm{SIV}^{-}$with four macaques in each group. PBO stands for placebo. THC was provided through NIH-funded research program from the National Institute on Drug Abuse (Research Technical Branch, Rockville, MD) at a concentration of $200 \mathrm{mg} / \mathrm{ml}$ in $100 \%$ ethanol. Upon arrival, $\Delta^{9}$-THC solution was stored in aliquots at $-20^{\circ} \mathrm{C}$, and prepared as an injectable emulsion. Consistently, chronic intramuscular injection of $\Delta^{9}$-THC occurred twice daily at 8:00 a.m. and 6:00 p.m. with a dose of $0.32 \mathrm{mg} / \mathrm{kg}$ for a total of 428 days. The dose and frequency of $\Delta^{9}$-THC $(0.32 \mathrm{mg} / \mathrm{kg}$, i.m., twice daily) were based on data previously generated in male rhesus macaques of Indian-origin (Molina et al. 2011b). PBO control animals received time-matched intramuscular injections of equal volumes $(0.05 \mathrm{ml} / \mathrm{kg})$ of diluent.

\section{Virus}

The challenge stock was prepared in rhesus peripheral blood mononuclear cells (PBMCs)

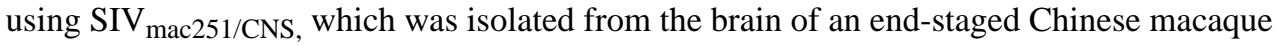
with simian AIDS and neurological disorders. The original SIV $_{\text {mac251 }}$ was kindly provided by Preston A. Marx. Macaques in groups one $\left(\Delta^{9}-\mathrm{THC}^{+} \mathrm{SIV}^{+}\right)$and three $\left(\Delta^{9}-\mathrm{PBO} / \mathrm{SIV}^{+}\right)$,

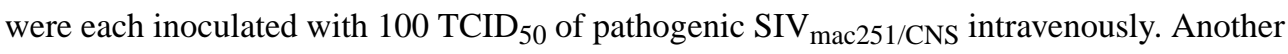
eight SIV-negative individuals groups two $\left(\Delta^{9}-\mathrm{THC}^{+} \mathrm{SIV}^{-}\right)$and four $\left(\Delta^{9}-\mathrm{PBO} / \mathrm{SIV}^{-}\right)$served as uninfected controls. 


\section{Viral load measurement by quantitative real-time RT-PCR}

RNA was isolated from $200 \mu$ of cell-free plasma using the QIAmp viral RNA minikit (Qiagen, Valencia, CA). The RNA was eluted in $20 \mu$ l of nuclease free water and frozen immediately at $-80^{\circ} \mathrm{C}$ until analysis. Plasma viral RNA loads were measured by a quantitative real-time reverse transcription-PCR (qRT-PCR) assay for SIV gag with the 5' primer GCAGA GGAGG AAATT ACCCA GTAC, 3'-primer CAATT TTACC CAGGC ATTTA ATGTT, and the probe FAM-ACCTG CCATT AAGCC CGA-MGB in the PerkinElmer ABI 7500 machine. Pre-standardized SIV $_{\text {mac251 }}$ gag $\mathrm{cDNA}$ was used as a positive control. Triplicate test reactions were performed for each sample.

\section{Phenotyping of peripheral T and B cells}

Peripheral blood samples were collected into ethylene diamine tetra-acetic acid (EDTA) anticoagulant tubes for the extraction and isolation of plasma by density gradient centrifugation. Flow cytometry was performed for the staining of $\mathrm{T}$ lymphocytes as we previously described (Chen et al. 2000; Chen et al. 2002; Wang et al. 2010). Peripheral $\mathrm{CD} 4{ }^{+} \mathrm{T}$-cell counts were calculated by multiplying the percentage of $\mathrm{CD} 3^{+} \mathrm{CD} 4{ }^{+} \mathrm{T}$ cells with the total $\mathrm{CD}^{+} \mathrm{T}$ lymphocytes using the BD Trucount ${ }^{\mathrm{TM}}$ method . One million peripheral blood mononuclear cells were stained with the following sets of monoclonal antibodies: CD8-PerCP (clone SK1), CD4-APC-Cy7 (clone SK3), CD3-PE (clone SP34), Ki-67-FITC (clone B56); IgE-APC (clone MB10-5C4), CD20-APC-Cy-7 (clone L27)(Xue et al. 2013). All the antibodies were purchased from BD Biosciences (San Jose, CA, USA). After washing with cold flow wash buffer, the cells were fixed with $1 \%$ paraformaldehyde and subjected to flow cytometry analysis within 24 hours. Samples were acquired and analyzed on a BD LSRII flow cytometer with the FACS DIVA Software (BD Biosciences). FACS data were evaluated using the FLOWJO Version 8.7 Software (Tree Star, Ashland, OR, USA).

\section{Statistical analysis}

Statistical analysis and graphical presentations were generated by GRAPHPAD PRISM software (GraphPad Software, La Jolla, CA, USA). One-way ANOVA analysis was performed for differences between multiple groups. Paired student $t$ test was used to compare intragroup data. Two-tailed and unpaired student $t$ tests were used for comparison between two groups. The Kaplan-Meier survival graph between two groups was analyzed with Log-rank test. The potential correlation between variables was analyzed with Pearson's correlation test. $\mathrm{P} \leq 0.05$ was considered statistically significant.

\section{Results \\ Chronic $\Delta^{9}$-THC administration does not enhance viral load and disease progression post SIV infection}

According to our experimental design (Fig. 1A), 16 male rhesus macaques of Chinese-origin were divided into four study groups: $\Delta^{9}-\mathrm{THC}^{+} \mathrm{SIV}^{+}(\mathrm{G} 1), \Delta^{9}-\mathrm{THC}^{+} \mathrm{SIV}^{-}(\mathrm{G} 2), \mathrm{PBO} / \mathrm{SIV}^{+}$ (G3) and $\mathrm{PBO} / \mathrm{SIV}^{-}(\mathrm{G} 4)$ with four macaques in each group. We aimed to determine the effects of chronic $\Delta^{9}$-THC on male Chinese macaques in the presence and absence of SIV 
infection. G1 and G2 animals received $\Delta^{9}$-THC daily for a total of 428 days. Thirty days after the pre- $\Delta^{9}$-THC treatment G1 and G3 macaques were challenged intravenously with 100 TCID $_{50}$ pathogenic SIV $_{\text {mac251/CNS }}$, whereas G2 and G4 served as uninfected PBO controls. The infection was successful because all animals in G1 and G3 displayed comparable peak viral load and steady-state viremia (Figs. 1B and 1C). The plasma viral loads reached their peak to approximately $10^{7}-10^{8}$ copies per $\mathrm{ml}$ around 14 days post viral inoculation in all eight infected macaques (Figs. 1B and 1C). The average viral loads of both groups were around $10^{5}$ copies per $\mathrm{ml}$ at steady state. Statistical analysis did not reveal any significance for both peak and steady-state viral loads between G1 and G3. Similar findings were also obtained when proviral loads were measured (data not shown). Chronic $\Delta^{9}$-THC, therefore, unlikely enhances viral loads during the course of SIV $_{\text {mac251/CNS }}$ infection. One macaque in G3 maintained high viral load and died of simian AIDS around 220 days post infection. Subsequently, another two infected animals, one in G3 and one in G1, died with relative high viral loads. Survival analysis, however, did not show statistical significance between G1 and G3 (Fig. 1C). Chronic $\Delta^{9}$-THC did not significantly alter disease progression during the course of $\operatorname{SIV}_{\text {mac251/CNS }}$ infection.

\section{$\Delta^{9}$-THC administration does not alter CD4 ${ }^{+} \mathbf{T}$ cell loss post SIV infection}

Besides viral load, $\mathrm{CD} 4^{+} \mathrm{T}$ cell count is another critical biomarker for measuring immunodeficiency and disease development during SIV infection. In order to further understand if chronic $\Delta^{9}$-THC affected CD4 T cells during the course of SIV infection, we measured CD4 count and CD4/CD8 ratio of each animal over time by standard protocols as we described previously (Chen et al. 2000; Chen et al. 2002). While viral loads reached peak around 14 days post infection, there were significant reductions of CD4 count among infected monkeys in both G1 and G3 (Fig. 2A, left). Moreover, the mean CD4 loss was clearly evident among SIV-infected animals in G1 and G3 throughout the chronic phase of infection but not among uninfected monkeys in G2 and G4 (Fig. 2A, right). There were, however, no significant differences in CD4 counts between G1 and G3 animals during both acute and chronic stages of infection. Chronic $\Delta^{9}$-THC alone did not seem to affect CD4 counts among uninfected macaques. In addition to CD4 count changes, $\mathrm{SIV}_{\text {mac251/CNS }}$ acute infection resulted in rapid drops of CD4/CD8 ratios in G1 and G3, which were not found with control animals in G2 and G4 (Fig. 2B, left). Subsequently, the mean CD4/CD8 ratios in G1 and G3 remained lower than those of uninfected animals in G2 and G4 (Fig. 2B, right). Critically, similar to CD4 counts, there were no overall statistical differences in $\mathrm{CD} 4 / \mathrm{CD} 8$ ratios between $\mathrm{G} 1$ and $\mathrm{G} 3$, suggesting that $\Delta^{9}$-THC administration did neither alter CD4 loss following SIV infection.

\section{SIV-induced proliferation of CD8+ $T$ cells contributes to abnormal CD4/CD8 ratios}

During SIV infection highly increased T-cell turnover and immune activation may cause exhaustion of $\mathrm{T}$ cell production and function in rhesus monkeys (Sopper et al. 2003). Because CB2 receptor is on the surface of T cells (Rom and Persidsky 2013), we aimed to investigate if $\Delta^{9}$-THC could influence T cell proliferation by measuring the expression of the $\mathrm{Ki}-67$ nuclear antigen in peripheral blood $\mathrm{CD}^{+}$and $\mathrm{CD} 8^{+} \mathrm{T}$ cell subpopulations. Similar to $\mathrm{CD} 4$ count changes described above, there were significant reductions of $\mathrm{Ki}-67^{+} \mathrm{CD} 4 \mathrm{~T}$ cell frequency among infected monkeys in both G1 and G3 while viral loads reached peak 
around 14 days post infection (Fig. 3A, left). There were no significant differences in $\mathrm{Ki}-67^{+} \mathrm{CD} 4 \mathrm{~T}$ cell frequency between $\mathrm{G} 1$ and $\mathrm{G} 3$ animals during both acute and chronic stages of infection. After the acute phase, the mean Ki- $67^{+} \mathrm{CD} 4 \mathrm{~T}$ cell frequency did not show distinct profiles when compared with uninfected animals in G2 and G4. More striking findings were made when $\mathrm{Ki}-67^{+} \mathrm{CD} 8 \mathrm{~T}$ cell frequency was analyzed. SIV $\mathrm{mac}_{\text {ma1/CNS }}$ infection resulted in a rapid increase in $\mathrm{Ki}-67^{+} \mathrm{CD} 8 \mathrm{~T}$ cell proliferation. There were rapid and significant increases of Ki- $67^{+} \mathrm{CD} 8 \mathrm{~T}$ cell frequency among infected monkeys in both G1 and G3 when compared with uninfected ones in G2 and G4 (Fig. 3B, left). Subsequently, the mean Ki- $67^{+} \mathrm{CD} 8 \mathrm{~T}$ cell frequency among SIV-infected animals in G1 and G3 was sustained at levels relatively higher than those of uninfected ones in G2 and G4 throughout the chronic phase of infection (Fig. 3B, right). Correlation analysis indicated that the $\mathrm{Ki}-67^{+} \mathrm{CD} 8 \mathrm{~T}$ cell frequency was somewhat inversely associated with the drop of CD4/CD8 ratios $(\mathrm{p}=0.041)$ but neither with viral load or nor with CD4 counts.

\section{Chronic $\Delta^{9}-\mathrm{THC}$ significantly reduced the frequency of peripheral $\lg \mathrm{E}^{+} \mathrm{B}$ cells overtime}

Because $\Delta^{9}$-THC administration did not seem to alter the course SIV infection during both acute and chronic phases, it raised a critical question on whether or not this active ingredient of Marinol was biologically active in experimental animals. To answer this question, we measured the body weights of each animal during the study period. The rationale was that $\Delta^{9}$-THC might improve food intake and, therefore, help to maintain a better body weight as compared with PBO groups. We, however, did not see statistical significance between G1 and G3 (or G2 and G4). Interestingly, one previous study indicated that $\Delta^{9}$-THC treatment influenced the production of $\mathrm{IgE}^{+} \mathrm{B}$ cells in vivo. Since $\mathrm{CB} 2$ receptor on the surface of $\mathrm{B}$ cells was found in IgE down-regulation in mice (Newton and Klein 2012), we sought to determine if $\Delta^{9}$-THC could affect $\operatorname{IgE}^{+} \mathrm{B}$ cells in experimental monkeys. We found that $\mathrm{SIV}_{\text {mac251/CNS }}$ infection led to rapid decreases of B cell frequency in both G1 and G3 at 14 days post infection (Fig. 4A, left), probably due to the rapid $\mathrm{CD}^{+} \mathrm{T}$ cell expansion among total lymphocytes. A similar trend was also found for $\mathrm{IgE}^{+} \mathrm{B}$ subsets but no statistical significance in this difference was achieved (Fig. 4B, left). Interestingly, there were significant differences on $\mathrm{IgE}^{+} \mathrm{B}$ cells using the one-way ANOVA under the Newman-Keuls analysis $(p<0.0001)$ when we compared these four groups during the time period of day 168-256. Regardless of SIV infection, when we compared $\Delta^{9}$-THC treated macaques in G1 and $\mathrm{G} 2(\mathrm{n}=8)$ with those of untreated in G3 and G4 $(n=8)$, there was an increased trend of total B cells among total PBMCs tested during this chronic steady stage of infection (e.g. day 231)(Fig. 4A, right). During the same time period, however, we found that the frequency of $\mathrm{IgE}^{+} \mathrm{B}$ cells was significantly reduced among eight macaques in $\mathrm{G} 1$ and $\mathrm{G} 2$ as compared with ones in G3 and G4 (Fig. 4B, right). After this time period, SIV infection in G3 probably led to the reduced frequency of $\operatorname{IgE}^{+} \mathrm{B}$ cells and, therefore, the statistical analysis was no longer significant.

\section{Discussion}

In this study, to the best of our knowledge we report the first study of cannabinoid effects on healthy and SIV-infected male rhesus monkeys of Chinese origin. Unlike $\Delta^{9}$-THC-mediated HIV-1 infection enhancement in huPBL-SCID mice (Roth et al. 2005) or $\Delta^{9}$-THC-associated 
plasma viral load reduction in SIV-infected male Indian macaques (Molina et al. 2011b), we found that $\Delta^{9}$-THC neither enhanced nor attenuated SIV $_{\text {mac251/CNS }}$ infection in our model system. This conclusion was based on our longitudinal study of viral loads, CD4 counts, $\mathrm{CD} 4 / \mathrm{CD} 8$ ratios, $\mathrm{T}$ cell proliferation, survival rate and clinical signs of disease progression in the context of continuous daily $\Delta^{9}$-THC administration for 428 days. We found that there were no significant differences in peak and steady state plasma viral loads as well as AIDS

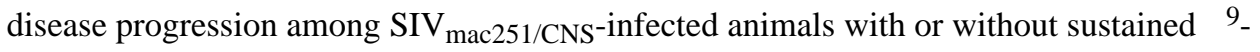
THC treatment. Moreover, regardless of $\Delta^{9}$-THC administration all infected macaques displayed significant drop of CD4/CD8 $\mathrm{T}$ cell ratios, loss of $\mathrm{CD}^{+} \mathrm{T}$ cells and higher levels of persistent $\mathrm{Ki} 67^{+} \mathrm{CD} 8^{+} \mathrm{T}$ cell proliferation when compared to uninfected animals. The main biological effects of $\Delta^{9}$-THC seen in this study, down-regulation of circulating $\operatorname{IgE}^{+} \mathrm{B}$ cells in vivo, warrants future studies to explore mechanisms involved.

The initial finding of $\Delta^{9}$-THC-attenuated progression of SIV-infection was made in male rhesus macaques of Indian origin (Molina et al. 2011a; Molina et al. 2011b). Using the same experimental protocols, we made similar observations in male rhesus macaques of Chinese origin in that $\Delta^{9}$-THC treatment of SIV-infected animals produced no significant effects on decreased CD4/CD8 ratio and increased $\mathrm{CD} 8^{+} \mathrm{T}$ cell proliferation. Moreover, two macaques in G3 died earlier than one in G1 after they developed clinical signs of disease (e.g. low CD4 count, weight loss and wasting). We, however, did not observe $\Delta^{9}$-THC-mediated attenuation of plasma viral loads or decreased early mortality of SIV infection with statistical significance. The differences observed between two monkey species might be due to multiple variable factors including the susceptibility of male Chinese macaques to $\Delta^{9}$ THC treatment and SIV infection, the optimal dose of $\Delta^{9}$-THC and different SIV strains inoculated. These are relevant factors because for example it has been previously documented that SIV $_{\text {mac251 }}$ infection displayed slower disease progression in Chinese macaques when compared with Indian macaques (Ling et al. 2002). If SIV-infected Chinese macaques are more relevant to HIV-1 infections in humans as suggested by others (Ling et al. 2002), our results demonstrated that the long-term course of $\Delta^{9}$-THC administration does not promote disease progression among infected male Chinese macaques, which is actually consistent to previous findings in male Indian macaques (Molina et al. 2011b). Since a recent study indicated that protection from early SIV mortality was not evident in $\Delta^{9}$-THCtreated female Indian macaques (Amedee et al. 2014), there is a need for future studies to explore the sex-dependent effects of $\Delta^{9}$-THC in female Chinese macaques or other nonhuman primate models as well as in humans.

Cannabis-based medications are commonly used off label for the treatment of anorexia, nausea, neuropathic pain and multiple sclerosis (Grotenhermen and Muller-Vahl 2012). Because cannabinoid receptor 2 (CB2) is expressed on the surface of $\mathrm{T}$ and $\mathrm{B}$ cells (Ameri 1999; Eisenstein and Meissler 2015; Gorantla et al. 2010; Kaplan 2013), the effect of $\Delta^{9}$ THC on immune system is of great interest for investigation. It was shown that $\Delta^{9}$-THC might enhance HIV-1 antigen-specific immune responses through CB1/CB2-dependent and independent mechanisms (Chen et al. 2015). A 21-day cannabinoid treatment protocol, however, did not exhibit significant effects on T/B cell phenotype and function among HIV-1 patients on HAART (Bredt et al. 2002). In this study, we found that the long-term $\Delta^{9}$-THC treatment did not seem to alter $\mathrm{T}$ cell growth and proliferation significantly either in 
uninfected or SIV infected macaques. Interestingly, we observed modest modulation of B cell growth in $\Delta^{9}$-THC-treated animals. In consistency to previous findings that cannabinoids enhance human B cell growth at low concentrations (Derocq et al. 1995), we found that the long-term administration of $\Delta^{9}$-THC was able to improve B cell frequency especially after 3 months of continuous treatment regardless of SIV infection. On one hand, this finding confirmed the biological activity of the long-term $\Delta^{9}$-THC treatment in male Chinese macaques. On the other hand, it calls for future investigation on whether or not this effect would impact anti-SIV humoral responses. To this end, another interesting finding in this study was the gradual loss of $\operatorname{IgE}^{+} \mathrm{B}$ cells in two $\Delta^{9}$-THC groups. Since CB2 is involved in the down-regulation of serum IgE levels in mice (Newton and Klein 2012), it is possible that the gradual loss of $\mathrm{IgE}^{+} \mathrm{B}$ cells was a consequence of $\mathrm{CB} 2$-mediated down-regulation of IgE in $\mathrm{B}$ cells by the long-term $\Delta^{9}$-THC administration. Future studies should test this hypothesis and the impact of $\Delta^{9}$-THC on other IgE-producing cells. Lastly, an elevated level of IgE has been studied clinically as a biomarker of poor prognosis in HIV-1 infected patients (Israel-Biet et al. 1992; Marone et al. 2000). Moreover, a negative correlation was found between the histamine-induced production of IFN $\gamma$ by HIV-1 specific $\mathrm{CD} 8^{+} \mathrm{T}$ lymphocytes and levels of total IgE (Hanzlikova et al. 2012). Although $\operatorname{IgE}^{+} B$ cells have been found in peripheral blood, thymus and other lymphoid organs during SIV and HIV-1 infections (Auci et al. 1997), their role in AIDS pathogenesis, inflammation and AIDSassociated higher rate of type 1 hyperactivity remains to be carefully investigated. Based on our findings on $\operatorname{IgE}^{+} \mathrm{B}$ cell reduction, the long-term $\Delta^{9}$-THC treatment could conceivably be beneficial in treating these diseases through CB2 modulation (Chandra et al. 2015; Persidsky et al. 2015; Picone and Kendall 2015). There are, however, some limitations of this study. For example, to mimic a large subset of humans who are infected with HIV-1, future experiments should look into the impact of $\Delta^{9}$-THC administered post-SIV infection. Drug dose-dependency and viral low dose repeat challenge experiments are needed to further determine the impact of $\Delta^{9}$-THC on susceptibility to SIV infection. The number of four animals in each group is small in this study, which may potentially affect the statistical analysis. The sensitivity and susceptibility of individual monkeys to $\Delta^{9}$-THC and SIV infection could also be variable. These limitations will require future investigation especially using a larger cohort of animals.

\section{Acknowledgement}

The authors would like to thank US NIH NIDA (3R01DA020419-02S1 to ZC and PM) and China's mega project 2012ZX10001006001009 for financial supports, David Shurtleff and Diane Lawrence for discussion and $\Delta^{9}$-THC arrangement, Xilin Wu and Yanxu Zhang for data analysis, and David Ho and KY Yuen for scientific advice. We also thank Hong Kong Research Grant Council HKU5/CRF/13G as well as the University Development Fund of the University of Hong Kong and Li Ka Shing Faculty of Medicine Matching Fund to HKU AIDS Institute.

\section{References}

Abrams DI. Medical marijuana: tribulations and trials. Journal of psychoactive drugs. 1998; 30:163169. doi:10.1080/02791072.1998.10399686. [PubMed: 9692378]

Amedee AM, et al. Chronic Delta(9)-tetrahydrocannabinol administration may not attenuate simian immunodeficiency virus disease progression in female rhesus macaques. AIDS research and human retroviruses. 2014; 30:1216-1225. doi:10.1089/AID.2014.0108. [PubMed: 25113915] 
Ameri A. The effects of cannabinoids on the brain. Progress in neurobiology. 1999; 58:315-348. [PubMed: 10368032]

Auci DL, et al. IgE-bearing cells and epsilon-specific mRNA in lymphoid organs of two children with AIDS Pediatric. AIDS and HIV infection. 1997; 8:102-107.

Bredt BM, Higuera-Alhino D, Shade SB, Hebert SJ, McCune JM, Abrams DI. Short-term effects of cannabinoids on immune phenotype and function in HIV-1-infected patients. Journal of clinical pharmacology. 2002; 42:82S-89S. [PubMed: 12412840]

Chandra LC, et al. Chronic administration of Delta9-tetrahydrocannabinol induces intestinal antiinflammatory microRNA expression during acute simian immunodeficiency virus infection of rhesus macaques. Journal of virology. 2015; 89:1168-1181. doi:10.1128/JVI.01754-14. [PubMed: 25378491]

Chen W, Crawford RB, Kaplan BL, Kaminski NE. Modulation of HIVGP120 Antigen-Specific Immune Responses In Vivo by Delta9-Tetrahydrocannabinol. Journal of neuroimmune pharmacology : the official journal of the Society on NeuroImmune Pharmacology. 2015; 10:344355. doi:10.1007/s11481-015-9597-x. [PubMed: 25900076]

Chen Z, et al. Enhanced infectivity of an R5-tropic simian/human immunodeficiency virus carrying human immunodeficiency virus type 1 subtype $\mathrm{C}$ envelope after serial passages in pig-tailed macaques (Macaca nemestrina). Journal of virology. 2000; 74:6501-6510. [PubMed: 10864663]

Chen Z, Zhao X, Huang Y, Gettie A, Ba L, Blanchard J, Ho DD. CD4+ lymphocytopenia in acute infection of Asian macaques by a vaginally transmissible subtype-C, CCR5-tropic Simian/Human Immunodeficiency Virus (SHIV). Journal of acquired immune deficiency syndromes. 2002; 30:133145. [PubMed: 12045675]

Croxford JL. Therapeutic potential of cannabinoids in CNS disease. CNS drugs. 2003; 17:179-202. [PubMed: 12617697]

Derocq JM, Segui M, Marchand J, Le Fur G, Casellas P. Cannabinoids enhance human B-cell growth at low nanomolar concentrations. FEBS letters. 1995; 369:177-182. [PubMed: 7544292]

Eisenstein TK, Meissler JJ. Effects of Cannabinoids on T-cell Function and Resistance to Infection. Journal of neuroimmune pharmacology : the official journal of the Society on NeuroImmune Pharmacology. 2015; 10:204-216. doi:10.1007/s11481-015-9603-3. [PubMed: 25876735]

Felder CC, Glass M. Cannabinoid receptors and their endogenous agonists. Annual review of pharmacology and toxicology. 1998; 38:179-200. doi:10.1146/annurev.pharmtox.38.1.179.

Gorantla S, Makarov E, Roy D, Finke-Dwyer J, Murrin LC, Gendelman HE, Poluektova L. Immunoregulation of a CB2 receptor agonist in a murine model of neuroAIDS. Journal of neuroimmune pharmacology : the official journal of the Society on NeuroImmune Pharmacology. 2010; 5:456-468. doi:10.1007/s11481-010-9225-8. [PubMed: 20549374]

Grotenhermen F, Muller-Vahl K. The therapeutic potential of cannabis and cannabinoids. Deutsches Arzteblatt international. 2012; 109:495-501. doi:10.3238/arztebl.2012.0495. [PubMed: 23008748]

Haney M. Effects of smoked marijuana in healthy and HIV + marijuana smokers. Journal of clinical pharmacology. 2002; 42:34S-40S. [PubMed: 12412834]

Haney M, Gunderson EW, Rabkin J, Hart CL, Vosburg SK, Comer SD, Foltin RW. Dronabinol and marijuana in HIV-positive marijuana smokers. Caloric intake, mood, and sleep. Journal of acquired immune deficiency syndromes. 2007; 45:545-554. doi:10.1097/QAI.0b013e31811ed205. [PubMed: 17589370]

Hanzlikova J, et al. Histamine increases the level of IFNgamma produced by HIV-1 specific CTLs and this production depends on total IgE level. Journal of immunological methods. 2012; 375:1-6. doi: 10.1016/j.jim.2011.10.006. [PubMed: 22037448]

Israel-Biet D, Labrousse F, Tourani JM, Sors H, Andrieu JM, Even P. Elevation of IgE in HIV-infected subjects: a marker of poor prognosis. The Journal of allergy and clinical immunology. 1992; 89:68-75. [PubMed: 1346148]

Kaplan BL. The role of CB1 in immune modulation by cannabinoids. Pharmacology \& therapeutics. 2013; 137:365-374. doi:10.1016/j.pharmthera.2012.12.004. [PubMed: 23261520]

Ling B, Veazey RS, Luckay A, Penedo C, Xu K, Lifson JD, Marx PA. SIV(mac) pathogenesis in rhesus macaques of Chinese and Indian origin compared with primary HIV infections in humans. Aids. 2002; 16:1489-1496. [PubMed: 12131186] 
Marone G, Florio G, Triggiani M, Petraroli A, de Paulis A. Mechanisms of IgE elevation in HIV-1 infection. Critical reviews in immunology. 2000; 20:477-496. [PubMed: 11396683]

Molina PE, Amedee A, LeCapitaine NJ, Zabaleta J, Mohan M, Winsauer P, Vande Stouwe C. Cannabinoid neuroimmune modulation of SIV disease. Journal of neuroimmune pharmacology : the official journal of the Society on NeuroImmune Pharmacology. 2011a; 6:516-527. doi: 10.1007/s11481-011-9301-8. [PubMed: 21830069]

Molina PE, et al. Modulation of gut-specific mechanisms by chronic delta(9)-tetrahydrocannabinol administration in male rhesus macaques infected with simian immunodeficiency virus: a systems biology analysis. AIDS research and human retroviruses. 2014; 30:567-578. doi:10.1089/AID. 2013.0182. [PubMed: 24400995]

Molina PE, et al. Cannabinoid administration attenuates the progression of simian immunodeficiency virus. AIDS research and human retroviruses. 2011b; 27:585-592. doi:10.1089/AID.2010.0218. [PubMed: 20874519]

Newton CA, Klein TW. Cannabinoid 2 (CB2) receptor involvement in the down-regulation but not upregulation of serum IgE levels in immunized mice. Journal of neuroimmune pharmacology : the official journal of the Society on NeuroImmune Pharmacology. 2012; 7:591-598. doi:10.1007/ s11481-012-9361-4. [PubMed: 22552780]

Persidsky Y, Fan S, Dykstra H, Reichenbach NL, Rom S, Ramirez SH. Activation of Cannabinoid Type Two Receptors (CB2) Diminish Inflammatory Responses in Macrophages and Brain Endothelium. Journal of neuroimmune pharmacology : the official journal of the Society on NeuroImmune Pharmacology. 2015; 10:302-308. doi:10.1007/s11481-015-9591-3. [PubMed: 25666933]

Pertwee RG. Pharmacology of cannabinoid CB1 and CB2 receptors. Pharmacology \& therapeutics. 1997; 74:129-180. [PubMed: 9336020]

Picone RP, Kendall DA. Minireview: From the bench, toward the clinic: therapeutic opportunities for cannabinoid receptor modulation. Molecular endocrinology. 2015; 29:801-813. doi:10.1210/me. 2015-1062. [PubMed: 25866875]

Riggs PK, Vaida F, Rossi SS, Sorkin LS, Gouaux B, Grant I, Ellis RJ. A pilot study of the effects of cannabis on appetite hormones in HIV-infected adult men. Brain research. 2012; 1431:46-52. doi: 10.1016/j.brainres.2011.11.001. [PubMed: 22133305]

Rom S, Persidsky Y. Cannabinoid receptor 2: potential role in immunomodulation and neuroinflammation. Journal of neuroimmune pharmacology : the official journal of the Society on NeuroImmune Pharmacology. 2013; 8:608-620. doi:10.1007/s11481-013-9445-9. [PubMed: 23471521]

Roth MD, Tashkin DP, Whittaker KM, Choi R, Baldwin GC. Tetrahydrocannabinol suppresses immune function and enhances HIV replication in the huPBL-SCID mouse. Life sciences. 2005; 77:1711-1722. doi:10.1016/j.lfs.2005.05.014. [PubMed: 15964028]

Sopper S, et al. Impact of simian immunodeficiency virus (SIV) infection on lymphocyte numbers and T-cell turnover in different organs of rhesus monkeys. Blood. 2003; 101:1213-1219. doi:10.1182/ blood-2002-06-1644. [PubMed: 12393472]

Srivastava MD, Srivastava BI, Brouhard B. Delta9 tetrahydrocannabinol and cannabidiol alter cytokine production by human immune cells. Immunopharmacology. 1998; 40:179-185. [PubMed: 9858061]

Wang H, et al. Acute infection of Chinese macaques by a CCR5-tropic SHIV carrying a primary HIV-1 subtype B' envelope. Journal of acquired immune deficiency syndromes. 2010; 53:285-291. doi: 10.1097/QAI.0b013e3181cc4f4a. [PubMed: 20051873]

Williams JC, Appelberg S, Goldberger BA, Klein TW, Sleasman JW, Goodenow MM. Delta(9)Tetrahydrocannabinol treatment during human monocyte differentiation reduces macrophage susceptibility to HIV-1 infection. Journal of neuroimmune pharmacology : the official journal of the Society on NeuroImmune Pharmacology. 2014; 9:369-379. doi:10.1007/s11481-014-9527-3. [PubMed: 24562630]

Xue J, et al. Repressive effect of primary virus replication on superinfection correlated with gutderived central memory CD4(+) T cells in SHIV-infected Chinese rhesus macaques. PloS one. 2013; 8:e72295. doi:10.1371/journal.pone.0072295. [PubMed: 24023734] 
a

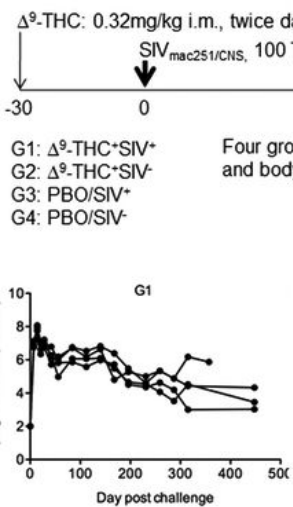

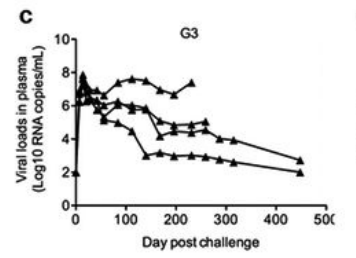

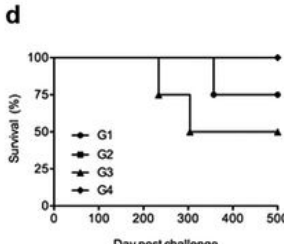

Fig. 1. Experimental design and SIV infection of male rhesus macaques of Chinese origin (A) Schematic representation of experimental timeline and groups. The arrows indicate the time schedule of $\Delta^{9}$-THC administrations and SIVmac251 challenge, respectively. (B). Peripheral blood viral loads of four G1 animals. (C) Peripheral blood viral loads of four G3 animals. (D) Survival analysis of four experimental groups of animals. 

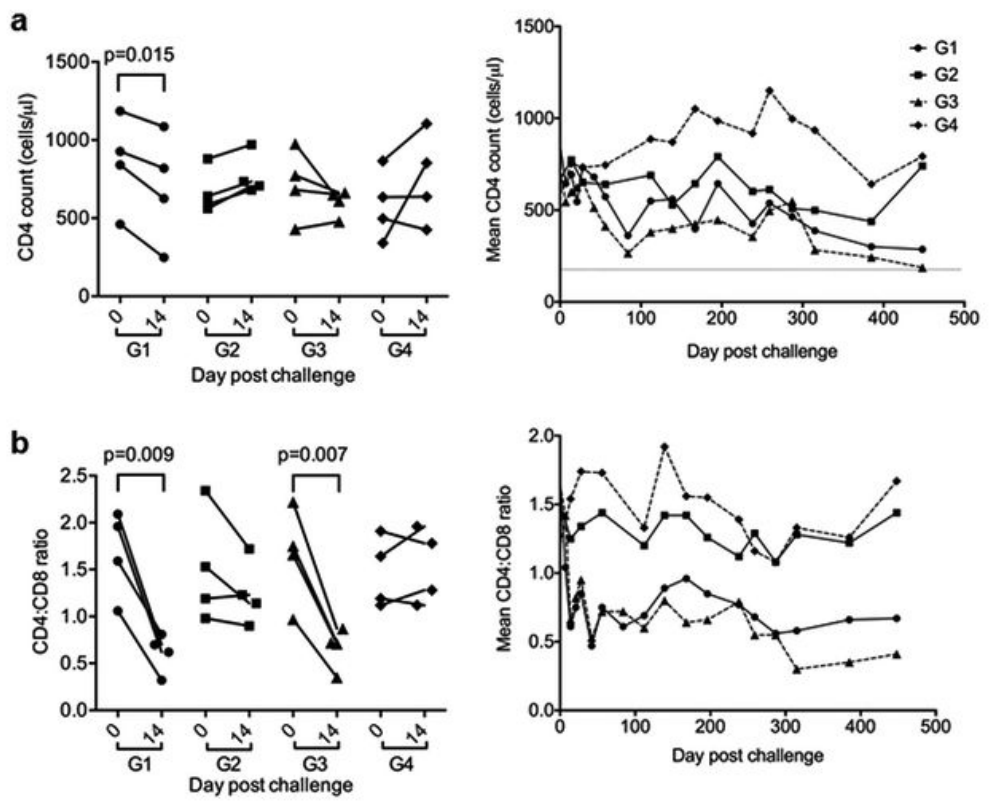

Fig. 2. Measurement of CD4 counts and CD4/CD8 ratios of all experimental macaques.

(A) CD4 counts or mean CD4 counts were measured at the acute phase of peak viremia on day 14 post infection (left) and overtime (right), respectively, by FACS analysis. (B) $\mathrm{CD} 4 / \mathrm{CD} 8$ ratios or mean $\mathrm{CD} 4 / \mathrm{CD} 8$ ratios were measured at the acute phase of peak viremia on day 14 post infection (left) and overtime (right), respectively, by FACS analysis. Paired student $t$ test was used to analyze the statistical significance for changes of CD4 counts and CD4/CD8 ratios in each animal. 

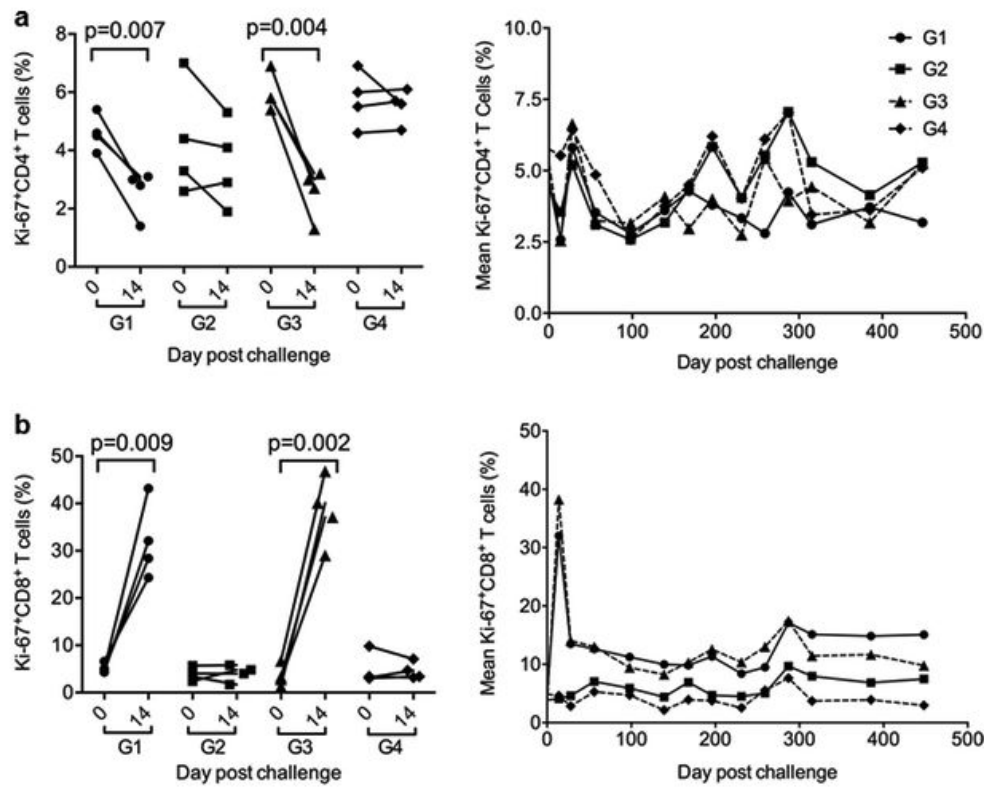

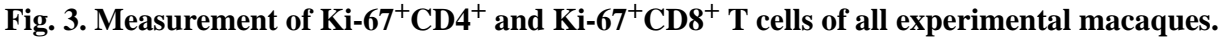
(A) Frequency of $\mathrm{Ki}-67^{+} \mathrm{CD} 4^{+} \mathrm{T}$ cells in each animal or mean frequency of $\mathrm{Ki}-67^{+} \mathrm{CD} 4^{+} \mathrm{T}$ cells in each group were measured at the acute phase of peak viremia on day 14 post infection (left) and overtime (right), respectively, by FACS analysis. (B) Frequency of $\mathrm{Ki}-67^{+} \mathrm{CD}^{+} \mathrm{T}$ cells in each animal or mean frequency of $\mathrm{Ki}-67^{+} \mathrm{CD} 8^{+} \mathrm{T}$ cells in each group were measured at the acute phase of peak viremia on day 14 post infection (left) and overtime (right), respectively, by FACS analysis. Paired student $t$ test was used to analyze the indicated statistical significance. 

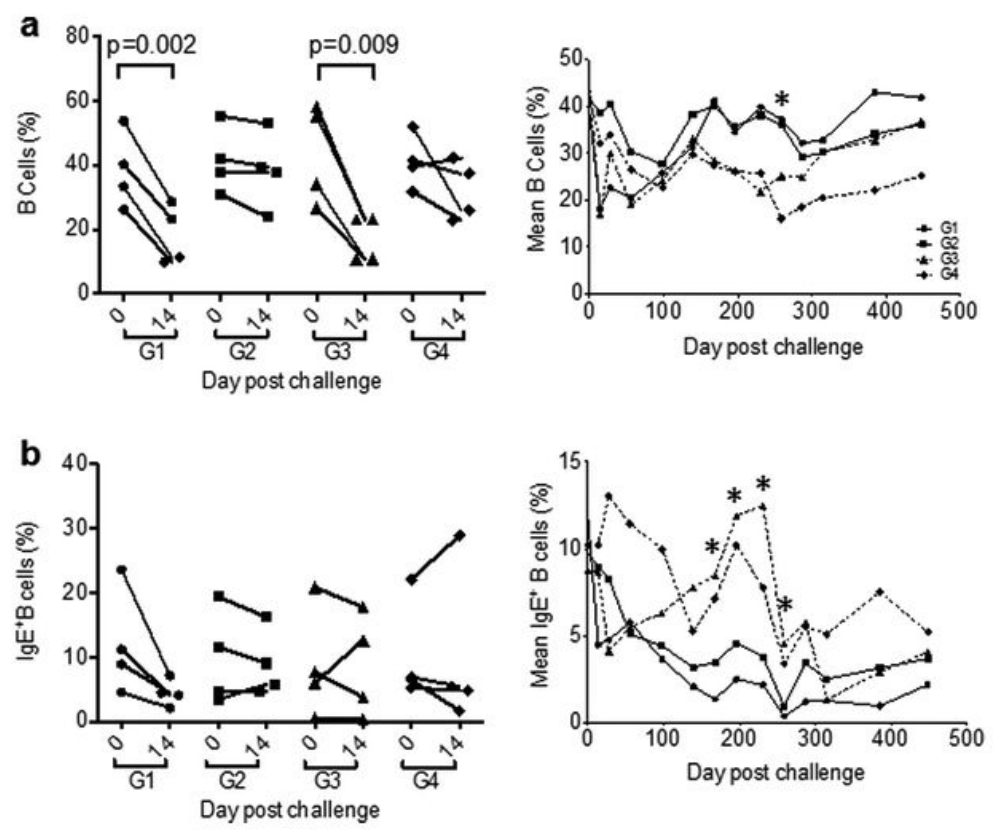

Fig. 4. Measurement of $\mathrm{CD20}^{+} \mathrm{B}$ cells and $\mathrm{IgE}^{+} \mathrm{B}$ cells of all experimental macaques

(A) Frequency of CD20 ${ }^{+}$B cells among lymphocytes in each animal or and mean frequency of cells in each group were measured at the acute phase of peak viremia on day 14 post infection (left) and overtime (right), respectively, by FACS analysis. (B) Frequency of $\operatorname{IgE}^{+} \mathrm{B}$ cells among total $\mathrm{CD} 20^{+} \mathrm{B}$ cells in each animal and mean frequency of $\mathrm{IgE}^{+} \mathrm{B}$ cells in each group were measured at the acute phase of peak viremia on day 14 post infection (left) and overtime (right), respectively, by FACS analysis. For statistic analysis, animals were divided into $\Delta^{9}$-THC treated $(\mathrm{n}=8)$ and untreated $(\mathrm{PBO})$ groups $(\mathrm{n}=8)$ regardless of SIV infection. Two-tailed and unpaired student $t$ tests were used for this comparison. 